\title{
CIENCIA Y LITERATURA EN ALFREDO COLLADO MARTELL: UN PRIMER CASO DE INSEMINACIÓN ARTIFICIAL
}

\author{
POR \\ WILLIAM ROSA \\ The William Paterson College \\ New Jersey
}

La posición que adoptan los modernistas hispanoamericanos ante los avances del progreso científico de la época, es de los aspectos más polémicos. Cierto es que desarrollan un código en el que el componente estético tiene un lugar privilegiado, como lo es también la profunda preocupación que les inspiran las condiciones socio-económicas que ha producido tanto la política nacional como la internacional. Esta visión crítica del cientificismo finisecular, señala Rafael Alberto Arrieta (50), tiende a identificar al "burgués" y al "científico como los adversarios de los valores representados por el artista. Mientras el "burgués" epitomiza el poder económico, materialista, el otro personifica, según los postulados de Michel Serres, ${ }^{1}$ el poder intelectual ofuente del conocimiento científico y complemento central del poder político. De ahí que los valores nuevos, de esta nueva clase social burguesa se van a oponer a los valores morales y espirituales tradicionales, cimentados en la verdad y la belleza. La confrontación entre los dos sistemas contrapone el realismo materialista decimonónico a la visión romántica del espacio hispanoamericano que se busca salvaguardar de los embates del progreso científico. Alfredo Collado Martell no sólo participa de estas preocupaciones, sino que examina la situación en su relato "Un hombre bueno que fue un hombre malo"."

\footnotetext{
${ }^{1}$ MichelSerres explica que la ciencia, al ser vista como un área absolutamente independiente de las humanidades, es transformada en "oficio" científico más que en mecanismo de indagación del conocimiento. Esta visión, necesariamente, la convierte en una estrategia de dominación basada en tácticas militares. El conocimiento científico, por lo tanto, es concebido como un "arte marcial" al servicio de las clases dominantes. De esta postura se desprende que la epistemologia del conocimiento es, en realidad, la epistemología del poder. De manera que, si se entiende la teoría de la ciencia como el componente fundamental de la dominación, entonces "conocer" es la ideología del mandato y la obediencia. Hermès. La Traduction, vol. III (París: Minuit, 1974).

2 Alfredo Collado Martell, "Un hombre bueno que fue un hombre malo", Cuentos absurdos (San Juan: Librería y Editorial Campos, 1931) 220-34. Todas las citas corresponden a esta edición, se señala la página en paréntesis.
} 
Collado Martell ilustra este choque en tres momentos claves de la vida del doctor Pedro Petroni. Su encuentro con don Sebastián Ochoa y Mir y su partida hacia Nueva York es el primero; los otros dos cubren los años posteriores a su regreso a Puerto Rico. El segundo ocurre a los pocos meses de regresar, y el tercero, cinco años después de haber nacido el hijo de Elvirita. Los cambios que experimenta Petroni, de una etapa a otra, llegan a subvertir el orden original, transformándolo de víctima en victimario, de pobre en rico, de "limpiabotas" en "burgués" y sobre todo, de analfabeto en "famoso" médico. Si al principio el limpiabotas carece de los recursos para satisfacer sus necesidades básicas y las de la madre, al final, el conocimiento científico que adquiere al emigrar a los Estados Unidos le pone en control del espacio que delimita su discurso. El acto de "inseminación artificial" constituye la mejor evidencia del cambio que se ha operadoen el doctor; el afán de venganza-dominación que desata en él el rechazo y la humillación que le hace sufrir don Sebastián, le hacen ver en Elvirita el vehículo de su empresa. Esta táctica lo eleva al primer nivel de la estructura falocrática del poder, según la describe Thorkil Vangaard; si cuando regresa a la isla ya controla los componentes intelectuales y económicos, ahora se impone sexualmente.

Paradójicamente, las palabras con que Petroni termina su discurso revelan a un hombre que, a pesar del éxito económico, el prestigio y la fama, vive "desilusionado" por haber transgredido sus principios morales. Cree que al adoptar el niño "chinito" que implantó en Elvirita podrá redimirse; sin embargo, éste le recuerda constantemente su falta al haber abusado de la confianza de ella. Ni siquiera su boda con Elvirita le brinda aliciente alguno, pues sabe muy bien que no hay amor entre ellos, sino agradecimiento de parte de ella y remordimientos de la suya.

Veamos en detalle la composición de cada uno de los momentos claves del discurso de Petroni, recordando que éstos son elementos de una estructura más amplia. El enfrentamiento entre el "limpiabotas" y don Sebastián sienta las bases ideológicas al mostrar la pugna entre los sectores sociales dominante y dominado (Rama 49-50) y, sobre todo, al distinguir claramente a los representantes de cada grupo.

El momento inicial comienza con don Sebastián al tope de las escaleras de mármol de su casa mientras Petroni aguarda a los pies de la misma. La localización de los personajes en la escena no sólo fija su posición socioeconómica - ricos us. pobres - sino que ilustra el choque de dos sistemas de valores diferentes; unos burgueses, materialistas, representados por don Sebastián, y los otros más tradicionales, si acaso ideales, representados por Petroni. Collado Martell reúne en don Sebastián las cualidades que identifican al burgués. Es blanco, alto y gordo, rico pero vulgar; más preocupado por las ganancias que espera de sus negocios que por la gramática de sus documentos. Mas el rasgo que mejor lo describe es su soberbia; ella es la responsable del ataque contra Petroni cuando éste es un niño y la que le provoca la muerte al 
nacer el hijo "chinito" de Elvirita. Es también la cualidad que mejor recuerda Petroni de su adversario y la que mantiene vivos sus deseos de venganzadominación.

Petroni personifica todo lo opuesto; es apenas un niño, pobre y huérfano, que trabaja como limpiabotas para mantener a la madre. Entra en contacto con la ciencia médica por primera vez a rá́z del puntapié que recibe de don Sebastián, el cual le produce una herida en la frente, de la que sangra profusamente, y la fractura del brazo derecho. Si el entablillado del brazo alivia el dolor físico de Petroni, la sangre de su frente será más difícil de lavar. La humillación (sangre) y la impotencia (fractura) que experimenta el niño ante la soberbia de don Sebastían exacerban sus deseos de dominación, hasta convencerlo de que la venganza es la única solución. Ésta va encaminada a restituirle su honor y sobre todo a hacerle pagar por la muerte de la madre. Irónicamente, diría Samuel R. Quiñones (7), la primera lección en la lucha por el poder fálico la recibe de don Sebastián, de aquél que ahora lo victimiza pero que luego será su víctima. Don Sebastián inicia la educación de Petroni, al demostrarle su vulnerabilidad, y éste la continúa en la ciudad de Nueva York, adonde emigra después de haber pedido ayuda en tres ocasiones y haber sido tres veces perseguido y castigado.

La confrontación entre don Sebastián y Petroni pone de manifiesto el espíritu materialista que critican los modernistas y su antídoto. La dicotomía que establece Collado Martell deslinda categóricamente los valores nuevos y mercantilistas de la clase dominante de los de aquéllos que representan una visión más tradicional del espacio hispanoamericano. El elemento fundamental, afirma Jean Franco (30), es el cambio de valores morales y espirituales que afectan la realidad de la América Latina en que se forman estos narradores, amenazándola con caducar. Por eso la reacción conservadora que producen los avances de la tecnología burguesa de la época tiene, en el ser arielista que propone Rodó, a su mejor aliado. ${ }^{3}$

El “acto de inseminación artificial" culmina la venganza de Petroni y, al mismo tiempo, marca el principio del conflicto moral y espiritual que sufrirá por el resto de su vida. Sin embargo, lo importante es haber logrado dominar y destruir además la soberbia de don Sebastián. Esto significa que ya no manda el pequeño burgués insular que lo humilló cuando era niño. Aquella fuerza bruta y hasta primitiva es reemplazada por otra que se apoya en el conocimiento científico adquirido en sus estudios médicos en los Estados Unidos. Este elemento, en conjunto con el poder económico y político que ha logrado, según

\footnotetext{
"Sarah Bollo llama a esta reacción "neo humanismo idealista", la cual tiene sus raíces en la Francia de Renán y Guyau. Ariel, es pues "un grito de alerta contra el utilitarismo y la plebeyez de la vida" y, al mismo tiempo, en favor de una cultura "integral", apoyada en los ideales clásicos de la latinidad. Sobre José Enrique Rodo (Montevideo: Impresora Uruguaya, S.A., 1955) 36-37.
} 
lo atestigua la prensa, convierte a Petroni en un adversario formidable para don Sebastián. De hecho, el padre de Elvirita pierde la vida en el conflicto mientras que ella pierde su honra "sin aun sentir la desfloración" (233).

Por otra parte, el "acto" provee al doctor del componente sexual necesario para completar su empresa. Si hasta ese momento ha logrado el poder económico y político a través de la ciencia médica, en el caso de Elvirita, Petroni no altera su método de trabajo; nuevamente, cada paso que toma ha sido cuidadosamente analizado. Una vez establecidos los objetivos del experimento, el doctor se transforma en "alquimista infernal" (229) y el sujeto estudiado en espécimen de laboratorio. Este cambio es el que justifica la "violación" de Elvirita, pues es el camino de que dispone Petroni para consolidar el poder fálico. Donna Haraway corrobora este hecho al indicar que el conocimiento científico es convertido en "techniques of social control instead of being transformed into sciences ofliberation"(125). Esta transformación es la que convierte al doctor en el burgués que conocimos al principio de la narración, el cual reproduce, en gran medida, la postura de don Sebastián. Antes fueron el niño y la madre quienes sienten el furor de la soberbia burguesa del "prohombre"; ahora la "virgen", parecida a una "muñeca adorable", es el objeto del afán de dominación de Petroni.

Además de culminar la venganza de Petroni, el "acto" ejemplifica el caso de dominación por excelencia; bajo él caen victimizadas la vida de don Sebastián, la virginidad de Elvirita y el respeto propio del doctor Petroni. Elvirita se somete al conocimiento técnico-científico del doctor, con la esperanza de reponerse de su malestar; sin embargo, éste se aprovecha de que está narcotizada, y abusa de su confianza al implantar la "semilla amarilla" (233) en ella. Irónicamente, Elvirita cree que el conocimiento de Petroni solucionará su problema, cuando en realidad es el responsable de su deshonra. Si al ponerse en las manos del médico piensa aliviar su dolencia, no logra reconocer que éste la utiliza para obtener sus propios objetivos. Una vez que reconoce en Elvirita a la víctima propiciatoria que hará posible su venganza, se lanza a su empresa amparado en su conocimiento científico. Su discurso describe paso por paso el método empleado en el "acto". ${ }^{4}$

El primero es recoger y preservar el semen de su sirviente chino, con el cual impregnará a la hija de don Sebastián. Es importante destacar que Petroni y hasta cierto punto Collado Martell - opta por utilizar el semen del oriental basado en sus estudios de medicina y sobre todo en las leyes de herencia propuestas por J. Gregor Mendel (1822-1884) durante la última parte del siglo

4Entre los estudios más completos sobre la inseminación artificial se pueden consultar: Elizabeth Noble, Having your Baby by Donor Insemination (Boston: Houghton Mifflin Co., 1987); LordKilbrandon, ed.Law and Ethics of A.I.D. and Embryo Transfer (The Hague: Associated Scientific Publishers, 1973);Wilfred J.Finegold Artificial Insemination (Springfield, ILL: Charles C. Thomas Publisher, 1964). 
XIX. ${ }^{5}$ Recogido el semen, el doctor lleva a cabo una serie de análisis, en los que mezcla la substancia viscosa con diferentes líquidos extraños; "Ya sereno, como un alquimista infernal, el doctor Petroni se encerró en su laboratorio" (229), dirá Collado Martell. Al final, cuando parece haber dado con la fórmula deseada, procede a preservarla en un horno eléctrico y a la temperatura del cuerpo. Debemos advertir que este último aspecto es el único que se aleja de los procedimientos modernos. Al día siguiente regresa Elvirita para ser examinada $y$, sin ella saberlo, es convertida en portadora de uno de los primeros casos de "inseminación artificial"; tan pronto ella es drogada comienza el experimiento. $\mathrm{El}$ afán de dominación que mueve al doctor domina aún su propio instinto sexual, el cual cede a sus deseos de venganza. Petroni no se aprovecha sexualmente de Elvirita porque sólo piensa en subyugar al padre de ésta; ella es sólo el medio para alcanzar el poder fálico que posee don Sebastián y que Petroni espera arrebatarle valiéndose de su conocimiento tecnológico-médico. Después de retirar el semen del horno, lo pone en una "jeringuilla diminuta, de pico de cristal" y pasa a inyectarlo en el "campo virgen" de Elvirita (233).

El "acto" tiene los resultados esperados por Petroni; no sólo con respecto al hijo de Elvirita, sino también en relación a don Sebastián. El dominio tecnológico-científico es la clave del éxito momentáneo del doctor, que cree haber alcanzado su meta; esto es, la humillación y la doblegación de don Sebastián a su poder. El "acto" per se es producto de la ciencia, y lo que lo produce el afán de dominio, el cual rebasa o incluye las diversas dimensiones del poder. En realidad, el "acto" aporta la dimensión sexual y el corolario de la estructura falocrática del poder.

Esta etapa en el proceso de conquista que ha emprendido Petroni tiene consecuencias imprevistas por él. Cierto es que humilla a don Sebastián al imponerle un nieto de raza china, considerada por su clase social como inferior a la de ellos. ${ }^{7}$ Sin embargo, el daño causado a Elvirita reviste una importancia

- Las teorias de la herencia de Mendel han suscitado numerosos estudios, entre los mejores están: R. Alexander Brink and E. Derek Styles, eds. Mendel Centennial Symposium. Heritage from Mendel (Madison: University of Wisconsin Press, 1967); Curt Stern, ed. ,The Origin of Genetics: A Mendel Source Book ( San Francisco: W. H. Freeman, 1966).

${ }^{6}$ El arte modernista, ha dicho Edgar Martínez Masdeu lleva, a través de sus temas, asuntos, metros y adjetivación inusitada un ataque contra el espíritu burgués de la época. Valiéndose de estos recursos llega a un arte aristocratizante, "fuera del alcance burgues" y para consumo de una "elite capaz de entenderlo y disfrutarlo". La critica puertorriqueña y el modernismo en Puerto Rico (San Juan: Instituto de Cultura Puertorriqueña, 1977) 29-30.

7 Juan Jiménez Pastrana, al estudiar el papel que jug6 la población asiática en Cuba en la segunda mitad del siglo XIX y principio del XX, dice que ésta pasa a sustituir a los esclavos africanos, después de que es promulgado y hasta cierto punto aceptado el cese de la trata negrera por España. Bajo la presión de los ingleses y de la burguesía criolla, el gobierno colonial legaliza la "contrata" de trabajadores "culies" para que tomen el lugar 
vital para Petroni pues además de violar su cuerpo virgen, destruye su “ilusión”, lo cual constituye un "delito mayor" (233).

Este "delito mayor" es el que denuncian los modernistas que veían los avances de la ciencia y la burguesía como una amenaza contra los valores tradicionales. El discurso de Petroni ejemplifica esta postura que critica las actitudes de don Sebastián al principio, y que al final se autocensura, cuando se da cuenta de que ha violado la belleza y la verdad personificadas en Elvirita.

El delito de Petroni es producto de su afán de dominación, que le ciega hasta el punto de que no va a poder reconocer que se ha convertido en lo que antes criticaba. La transformación supone un arma de opresión más sofisticada que laempleada por don Sebastián, pues combina las dimensiones físicae intelectual de la relación burgués/artista. Ya no es sólo el poder económico el que predomina en el ejercicio del poder fálico, sino la confluencia de diferentes sistemas, con base en el conocimiento científico y tecnológico.

El único componente del poder fálico que Petroni no controla, el sexual, lo obtiene a través de Elvirita y el "acto de inseminación artificial". Sin embargo, una vez que comprende la magnitud de sus acciones, sabe que ha cometido un crimen muy parecido al de su adversario. Este momento "anagnórico" produce en él un profundo vacío, ocupado anteriormente por su humildad, su nobleza de carácter y su amor por la madre. Reconoce también que estas cualidades han sido reemplazadas por su afán de dominación y dirigidas contra la "muñeca adorablen.

El "acto" viola la imagen de belleza-verdad suprema que representa Elvirita, y que se establece durante su primera visita al consultorio de Petroni. Elvirita, que se distingue de sus padres tanto por su belleza física como moral, ha estudiado música y pintura, pero más que nada, ha adquirido "maneras de artista" (227), lo cual la coloca en una dimensión superior a la de su padre, quien vive apegado a unos valores materialistas. ${ }^{8}$ La singularidad emocional del artista para interactuar con su espacio a diferentes niveles y de diferentes maneras es el rasgo que subraya el discurso. Más que la oposición de las dimensiones física y espiritual, los modernistas buscan la forma de armonizarlas, por eso Elvirita ofrece su hermosura y su honra en sacrificio por el alma de

de los africanos. Las condiciones de vida del sector generador de la riqueza que disfruta la clase dominante no se altera en absoluto. Son tan explotados y abusados como antes lo fueron los africanos y los indios, y como éstos, muy pronto se alían a los diferentes movimientos revolucionarios. Los chinos en las luchas por la liberación cubana 18471930. (La Habana: Instituto de Historia, 1963).

${ }^{8}$ Iver S. Verdugo señala que el arte, porque atraviesa las barreras temporales, recupera para la inmortalidad el transcurso fugaz de la existencia. La poesía y la belleza, subraya el critico, por estar protegidas por Dios, trascienden el plano material y dignifican al artista. "Introducción" a Cuentos de Rubén Darío. (Buenos Aires: Editorial Kapelusz, 1971) $23,26$. 
Petroni. Esta canonización de la protagonista llega a su culminación cuando se transforma en "verdadera impresión de muñeca adorable" (227); la transformación, hemos dicho en otra ocasión, supone que la belleza prístina de Elvirita, al remedar la belleza ideal se convierte en obra de arte, y por lo tanto, superior a la materia. La escena cierra con una visión de ella, en la que los aspectos físico y espiritual tienen como base la inocencia de la niñez; Elvirita es entonces: "la niña preciosa y adorable" (227).

Esta idealización de Elvirita sugiere que hay posibilidades de redención para Petroni. Desde el instante en que el doctor reconoce su falta se lanza a su reparación con mayor ímpetu del que mostró para la venganza. Petroni recuerda que el "acto" y ahora los instrumentos que utilizó para cometer su crimen son "los mismos aparatos" (232), renegando por haberlos usado. Al final se nos dice que ha adoptado al "niño artificial" (233) de Elvirita y que se ha casado con ésta para salvarla de la humillación pública y la deshonra. Sin embargo sabe que no tiene el amor de ella sino su agradecimiento, dando por sentado que no podrá disfrutar del verdadero amor conyugal, en el que convergen sus manifestaciones espiritual y corporal. Petroni expia su culpa por mediación de los que sufrieron el furor de su poder; éstos son el vehículo que le permitirá rebasar las limitaciones que le impuso su soberbia.

Como hemos visto, Collado Martell aborda la problemática científica de principios de siglo desde una perspectiva análoga a la de otros modernistas; la característica más singular de su discurso es el medio empleado para ilustrar los alcances del poder intelectual-científico. El espíritu burgués, el cual es visto como el propulsor de unos valores morales y espirituales opuestos a aquéllos que representa el artista, tiene en la ciencia y su control uno de sus aliados más fuertes. Petroni logra vencer y destruir a don Sebastián gracias a las armas "nuevas" que le provee la ciencia, pues le permite ejercer un control más radical en la medida en que domina diferentes espacios.

El "caso" muestra en toda su magnitud el poder falocrático de que dispone el hombre para imponerse sobre la mujer y la organización social. El "caso", en realidad, representa la consolidación del poder fálico de Petroni, y simultáneamente, la anagnórisis que revive en él unas preocupaciones más trascendentales. Éstas, a su vez, propician su reivindicación moral y espiritual. Al parecer, Collado Martell propone que de la contienda modernista entre los

\footnotetext{
${ }^{9}$ Collado Martell ilustra también esta ambivalencia a través de la figura de Hamlet, con la cual Petroni se compara en tres ocasiones, al debatirse si seguir adelante con el "acto" o si acudir a otro método para consumar su venganza. Cirlot señala que Hamlet representa al hombre arquetípico, Edipo, que sufre por estar atado al mundo material, por ser una entidad material, y por deber su existencia a un ser que él matará. Al mismo tiempo, Hamlet simboliza el hombre en rebelión contra la situación filial, en la que es símbolo humanizado y cristianizado del sucesor del "Prometeo" de Esquilo y el "Satanás" de Milton. A Dictionary of Symbols, trans. Jack Sage (New York: Philosophical Library, 1971) 136.
} 
valores tradicionales representados por el artista y los nuevos, representados por el burgués y la ciencia, no surge un vencedor y un vencido aunque sí se reafirma la supremacía del arte sobre la materia.

\section{Obras Citadas}

Arrieta, Rafael Alberto. Introducción al modernismo literario. Buenos Aires: Editorial Columba, 1961.

Franco, Jean. La cultura moderna en América Latina. México: Joaquín Mortiz, 1971.

Haraway, Donna. "Animal Sociology and a Natural Economy of the Body Politics, Part I: A Political Phisiology of Dominance". The Signs Readers, Elizabeth Abel and Emily K. Abel, eds. Chicago and London: The University of Chicago Press, 1983.

Quiñones, Samuel R. "Úmbral", Cuentos absurdos. San Juan: Librería y Editorial Campos, 1931.

Rama, Angel. Rubén Darío y el modernismo. Caracas: Ediciones de Biblioteca de la universidad Central de Venezuela, 1970.

Rosa, William. "La última aventura del Patito Feo' o las posibilidades de un símbolo". Revista de Estudios Hispánicos 22, 1989.

Vangaard, Thorkil. Phallos: A Symbol and Its History in the Male World. New York: International Universities Presses, Inc., 1972. 